\title{
Clinic-Based Food Assistance is Associated with Increased Medication Adherence among HIV-Infected Adults on Long-Term Antiretroviral Therapy in Zambia
}

\section{Nyasha Tirivayi ${ }^{1}$, John R Koethe ${ }^{2,3 *}$ and Wim Groot ${ }^{4}$}

${ }^{1}$ Maastricht Graduate School of Governance, Maastricht University, Maastricht, The Netherlands

${ }^{2}$ Centre for Infectious Diseases Research in Zambia, Lusaka, Zambia

${ }^{3}$ Division of Infectious Diseases, Vanderbilt University School of Medicine, Nashville, Tennessee, USA

${ }^{4}$ Department of Health Services Research, Maastricht University, Maastricht, The Netherlands

\begin{abstract}
Background: There has been limited research to date on the effects of food assistance provided to HIV-infected adults in resource-constrained settings with a high prevalence of malnutrition and chronic food insecurity. We compare antiretroviral therapy (ART) adherence, weight gain, and CD4+ lymphocyte count change among HIVinfected adults enrolled in a clinic-based food assistance program in Lusaka, Zambia versus a control group of non-recipients.
\end{abstract}

Methods: We conducted a cohort study incorporating interviewer-administered surveys and retrospective clinical data to compare ART patients receiving food assistance with a control group of non-recipients. Medication adherence was assessed using pharmacy dispensation records. We use propensity score matching to assess the effect of food assistance on outcome measures.

Results: After 6 months, food assistance recipients $(n=145)$ had higher ART adherence compared to nonrecipients ( $n=147,98.3 \%$ versus $88.8 \%$, respectively; $p<0.01$ ), but no significant effects were observed for weight or CD4+ lymphocyte count change. The improvement in adherence rates was greater for participants on ART for less than 230 days, and those with BMl $<18.5 \mathrm{~kg} / \mathrm{m}^{2}$, a higher HIV disease stage, or a CD4+ lymphocyte count $\leq 350$ cells/ $\mu$ l.

Conclusions: Promoting optimal medication adherence among persons on ART is relevant to public health and the success of HIV control efforts. The provision of food assistance to HIV-infected adults on ART may have an incentivizing effect which can improve medication adherence, particularly among patients recently initiated on treatment and those with poor nutrition or advanced disease. The effects on body weight and immune reconstitution appear minimal.

Keywords: HIV; Antiretroviral therapy; Nutrition; Africa; Food insecurity; Medication adherence

Abbreviations: ART: Antiretroviral Therapy; ATT: Average Treatment effect on the Treated; BMI: Body Mass Index; MPR: Medication Possession Ratio; WFP: World Food Program; WHO World Health Organization.

\section{Background}

Although the geographic overlap of malnutrition and chronic food insecurity in many areas of sub-Saharan Africa with high HIV infection prevalence is widely seen as a barrier to optimal antiretroviral therapy (ART) outcomes, the role of nutrition supplementation within comprehensive HIV treatment programs is not well defined. Food insecurity is associated with poor health status, more frequent opportunistic infections, and reduced ART adherence, while chronic undernutrition increases functional immunosuppression and reduces the capacity for physical and labor activity [1-5]. A Body Mass Index (BMI) less than $18.5 \mathrm{~kg} / \mathrm{m}^{2}$ is a general indicator of a poor nutritional state and has emerged as a powerful predictor of mortality among HIV-infected adults initiating ART in resource-limited settings, and HIV-affected households are more likely to be food insecure, which negatively impacts nutrition for both the HIV-infected member and other household members [6-9]. Food assistance may have a role in incentivizing patients to collect medications as scheduled, and sufficient nutrition may have a role in increasing medication tolerability and promoting nutritional rehabilitation [10-12].
Given the reported association between food insecurity and suboptimal ART outcomes, some HIV care and treatment programs dispense food assistance as a component of medical care, with the twin goals of improving health outcomes and boosting household food security. Prior studies have primarily investigated the effect of macronutrient supplementation on mortality or other clinical endpoints in the immediate post-ART period among HIV-infected adults in resource-limited settings [13-16]. An evaluation of clinicbased food assistance for individuals starting ART during the rapid scale-up of treatment services in Zambia in 2004 reported greater medication adherence among food recipients [17], while a similar study in Haiti found greater attendance at monthly clinic visits [12] There are few data, however, on the effect of targeted food assistance

${ }^{*}$ Corresponding author: John R. Koethe MD, MS, Division of Infectious Diseases, Vanderbilt University Medical Center, A2200-MCN, 1161 21st Avenue South Nashville, USA, Tel: 37232-2582, Office : 615-322-2035; Fax : 615-343-6160 E-mail: john.r.koethe@vanderbilt.edu

Received August 24, 2012; Accepted September 21, 2012; Published September 24, 2012

Citation: Tirivayi N, Koethe JR, Groot W (2012) Clinic-Based Food Assistance is Associated with Increased Medication Adherence among HIV-Infected Adults on LongTerm Antiretroviral Therapy in Zambia. J AIDS Clinic Res 3:171. doi:10.4172/2155 6113.1000171

Copyright: (C) 2012 Tirivayi N, et al. This is an open-access article distributed under the terms of the Creative Commons Attribution License, which permits unrestricted use, distribution, and reproduction in any medium, provided the original author and source are credited. 
Citation: Tirivayi N, Koethe JR, Groot W (2012) Clinic-Based Food Assistance is Associated with Increased Medication Adherence among HIV-Infected Adults on Long-Term Antiretroviral Therapy in Zambia. J AIDS Clinic Res 3:171. doi:10.4172/2155-6113.1000171

for individuals on long-term ART (i.e., months to years since treatment initiation) during periods of increased food insecurity, despite frequent scarcity and price fluctuations in many parts of sub-Saharan Africa, and the higher medication costs of for patients failing first-line ART regimens. In this analysis, we compare ART adherence and the change in weight and CD4+ lymphocyte count between food insecure, HIVinfected Zambian adults on long-term treatment enrolled in a 6-month clinic-based food assistance program versus a matched control group which did not receive assistance.

\section{Methods}

\section{Overview of the food assistance program}

The World Food Program-Zambia (WFP) food assistance initiative for HIV-affected individuals and households in Lusaka, Zambia was launched in February 2009 and designed to provide beneficiaries with 12 months of support. The program was launched in response to increased food insecurity in the region resulting, in part, from recent drought conditions and increased prices for commodities. The monthly ration was comprised of maize (25 kg), vegetable oil (1.8 liters), peas $(4.5 \mathrm{~kg})$, and a corn and soy blend flour $(6.0 \mathrm{~kg})$. The monthly ration had a market value of approximately US\$18 in 2009.

All ART patients at the beneficiary clinics were eligible for the food insecurity evaluation, and poor clinical nutrition status (e.g., low BMI) was not a requirement for enrollment. The individual targeting criteria for food assistance were based on a poverty and food insecurity screening questionnaire which assessed household size and composition, the number of HIV-infected members, asset ownership, employment status, income, housing characteristics, child education and household dietary diversity. Patients were included in the food assistance programme if they scored above a certain cutoff score deemed to indicate food insecurity. Patients who scored below this threshold were excluded from the food assistance programme. In this analysis we refer to the food assistance recipients as the intervention group and non-recipients as the control group.

\section{Data collection}

This study uses both primary interview data and secondary (previously collected) clinical data. After 6 months of the food assistance program implementation, we sampled four Lusaka publicsector ART clinics that distributed food rations (Mtendere, Chawama, Kanyama, and George), and four control clinics that did not distribute rations (Bauleni, Chipata, Matero Reference, and Chilenje). To provide a rough equivalence between the intervention and control groups and to control for probable clinic effects, control clinics were selected to match intervention clinics according to three criteria: active patient population, duration of operation, and historical patient survival at 12 and 18 months post-ART initiation (Table 1). All clinics were public-sector facilities serving low-income areas of Lusaka, and the socioeconomic characteristics of the surrounding area were also considered by the investigators when selecting the final pairs.

Random sampling was used to select approximately 50 nonpregnant adult ART patients from each of the four intervention clinics and a similar number of patients from each control clinic. The control patients were screened using the same food insecurity questionnaire utilized for the food assistance program, and only individuals meeting the eligibility criteria were included as controls. To minimize selection bias, interviewers were blinded to the study hypotheses and outcomes. All study participants were administered a household questionnaire based on previously validated research tools to capture socio-economic data including patient demographics, employment status and household level variables such as house ownership, number of HIVinfected household members, number of disabled household members, household size, asset ownership and energy sources. The questionnaire was refined through pre-testing at the Bauleni and Chawama clinics. After the survey was completed, a list of the 400 interviewees was provided to the Smartcare national ART programme database custodian for verification of ART programme enrolment and collection of data on duration of ART treatment, WHO disease stage, CD4+ lymphocyte counts, weight measurements, and dates of clinic and pharmacy visits.

Patients were included in the analytical sample if they had an initial laboratory value or pharmacy visit within 60 days of January 1,2009 (the month immediately prior to the start of the assistance program), and a subsequent value or visit 90 to 270 days from this date. This approach has been used by previous similar studies $[18,19]$. We used the medication possession ratio (MPR) as the measure of ART adherence, which calculates the proportion of days a patient has medication available by dividing the total number of days the patient was late for pharmacy refills (i.e., days after previous dispensation was exhausted) by the total days on ART during the study period. This ratio is subtracted from 1 and converted into percentages [20]. The MPR appraises pill possession and has been validated as a predictor of poor immune reconstitution, virologic failure, and the development of drug resistance mutations [20-22]. Prior studies have demonstrated that an adherence level above 95\% (i.e., optimal adherence) is associated with a significantly lower risk of virologic failure and the development of

\begin{tabular}{|c|c|c|c|c|c|c|c|}
\hline \multirow[t]{2}{*}{ Study clinic pair } & \multirow{2}{*}{$\begin{array}{l}\text { Duration of operation } \\
\text { (Months) }\end{array}$} & \multirow{2}{*}{ Active patients } & \multirow{2}{*}{$\begin{array}{l}\text { Patients on } \\
\text { food aid (\%) }\end{array}$} & \multicolumn{2}{|l|}{ Percent sampled } & \multirow{2}{*}{12 month survival ${ }^{\dagger}$} & \multirow[t]{2}{*}{18 month survival $^{\dagger}$} \\
\hline & & & & Among clinic population & $\begin{array}{l}\text { Among food } \\
\text { assistance recipients }\end{array}$ & & \\
\hline Kanyama & 64 & 4296 & $1600(37 \%)$ & $1.2 \%$ & $3.1 \%$ & 0.94 & 0.93 \\
\hline Matero Reference & 60 & 5355 & $\mathrm{n} / \mathrm{a}$ & $0.93 \%$ & $n / a$ & 0.94 & 0.93 \\
\hline Chawama & 41 & 3875 & $700(18 \%)$ & $1.3 \%$ & $7.1 \%$ & 0.91 & 0.90 \\
\hline Chipata & 54 & 4543 & n/a & $1.1 \%$ & $n / a$ & 0.86 & 0.85 \\
\hline George & 60 & 4097 & $680(17 \%)$ & $1.2 \%$ & $7.4 \%$ & 0.90 & 0.88 \\
\hline Chilenje & 59 & 3273 & $n / a$ & $1.5 \%$ & n/a & 0.93 & 0.91 \\
\hline Mtendere & 64 & 2896 & 708 (24\%) & $1.7 \%$ & $7.1 \%$ & 0.89 & 0.88 \\
\hline Bauleni & 56 & 1400 & $\mathrm{n} / \mathrm{a}$ & $3.6 \%$ & $\mathrm{n} / \mathrm{a}$ & 0.91 & 0.89 \\
\hline
\end{tabular}

Food assistance clinics in bold italics; table stratified by study/control clinic pairs. The criteria for matching food assistance and control clinics were duration of operation, population of active patients, and 12 and 18 month survival. All clinics were public-sector facilities serving low-income areas of Lusaka, and similarity of the local environment was also considered in selecting final pairs.

'Through August 2009

tKaplan-Meier estimate of the proportion of patients surviving at 12 and 18 months post-ART initiation

Table 1: Characteristics of study clinic pairs. 


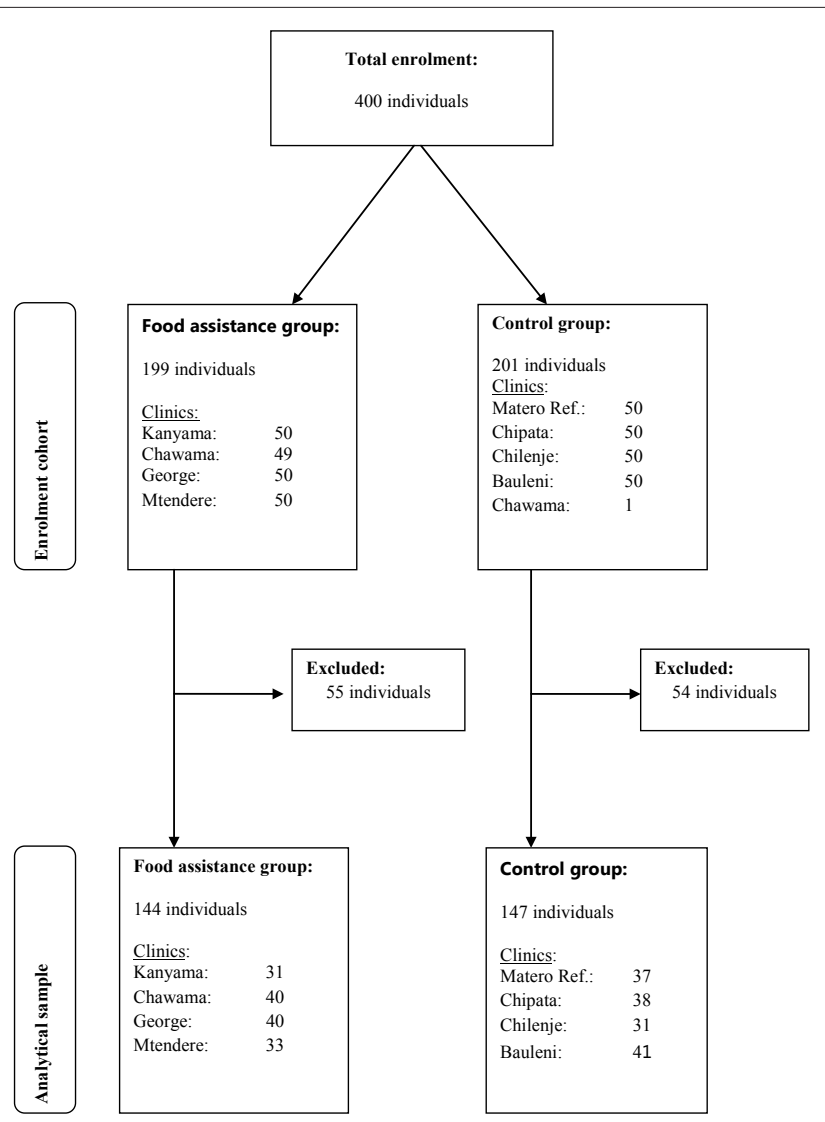

Figure 1: Participant enrolment and final clinical analysis cohort.

antiretroviral resistance mutations [20,23], while the risk of virologic failure increases with incremental reductions in the MPR below $95 \%$ $[20,21]$.

Patients were excluded from the analytical sample if no medical record number was documented during the interview or the documented number could not be located in the database. Additionally, participants were excluded if they were $<18$ years of age; were registered as a patient at the corresponding interview site but had no recorded clinical visits after 1st January, 2009; did not have a recorded clinic visit during the study initiation period (1st January to 1st March, 2009); were not on ART; or were registered as a patient in the national ART database but had no recorded visits to the corresponding interview site at any time. One patient registered as being in care at a non-beneficiary clinic was inadvertently surveyed at a food assistance clinic (Chawama), and this person was excluded from analysis to avoid contaminating the sample. One-hundred and nine patients (27\%) were excluded due a lack of sufficient laboratory or clinical data in the window periods. The final analysis cohort had 144 patients in the intervention group and 147 patients in the control group. The selection process is illustrated in figure 1.

\section{Statistical analysis}

While our analysis matched control clinics to intervention clinics on several parameters (mortality, clinic size, and duration of operation), there may have been social or economic differences between clinic populations. We used propensity score matching (PSM) to adjust for observed differences in characteristics and potential unknown selection bias which allowed for the estimation of the average effect of food assistance on the intervention group, known as the average treatment effect on the treated' (ATT). PSM matches observed characteristics of food assistance participants to non-participants based on similar values of the propensity score, which we obtained using the 'probit' estimation of the likelihood of an ART patient receiving food assistance based on pre-intervention characteristics. We then used these estimators to match patients receiving food assistance to control patients with the nearest estimated propensity score using the method of Leuven and Sianesi [24]. Patients were matched using the kernel estimator (with replacement) and the common support condition was imposed [25]. This ensures that patients with similar observed characteristics have a positive probability of being both participants and non-participants [25]. For the analysis of CD4+ lymphocyte and BMI change, we combined 'difference in differences' estimation with PSM to remove potential bias from unobservable factors and from all time-invariant unmeasured factors between the treatment and control group [26]. The 'difference in differences' impact estimation calculates the overall difference between pre- and post-differences in outcomes of the intervention and control groups.

The variables used to obtain the propensity score were age, gender and education level of the participant; the severity of illness at ART initiation (i.e. WHO disease stage 3 or 4); marital status, employment status, household size, asset ownership, house ownership, and reliance on charcoal instead of electricity for cooking; the number of HIVinfected and the number of disabled household members; the distance from the patient's residence to the clinic; and the local area population (a community-level characteristic).

\section{Ethical approval}

This study was conducted with the approval of the University of Zambia Research Ethics Committee and the Ministry of Health of the Republic of Zambia.

\begin{tabular}{|l|l|l|l|}
\hline & $\begin{array}{l}\text { Intervention } \\
\text { Group (N=144) }\end{array}$ & $\begin{array}{l}\text { Control Group } \\
(\mathbf{N}=147)\end{array}$ & p-value \\
\hline Demographics & $41(0.8)$ & $40(0.6)$ & 0.10 \\
\hline Age in years, mean (SE) & $80 \%(115)$ & $73 \%(107)$ & 0.16 \\
\hline Female sex, \% (n) & & & \\
\hline WHO Stage, \% (n) & $59 \%(53)$ & $82 \%(79)$ & $<0.01$ \\
\hline I or II & $37 \%(34)$ & $17 \%(16)$ & $<0.01$ \\
\hline III & $6 \%(6)$ & $1 \%(1)$ & 0.05 \\
\hline IV & $366(21)$ & $365(20)$ & 0.97 \\
\hline $\begin{array}{l}\text { CD4+ lymphocyte count , mean cells/ } \\
\mu l\end{array}$ & $777(44)$ & $864(42)$ & 0.15 \\
\hline ART in days, mean (SE) & & & \\
\hline Body mass index, mean kg/m²(SE) & $20.7(0.3)$ & $21.5(0.4)$ & 0.06 \\
\hline All participants & $21.1(0.4)$ & $22.0(0.4)$ & 0.12 \\
\hline Female & $19.2(0.4)$ & $20.3(0.4)$ & 0.06 \\
\hline Male & & & 0.26 \\
\hline Other characteristics & $12 \%(24)$ & $14 \%(33)$ & 0.21 \\
\hline No education, \% (n) & $43 \%(62)$ & $47 \%(69)$ & 0.51 \\
\hline Married, \% (n) & $4.9(0.1)$ & $4.9(0.1)$ & 0.82 \\
\hline Household size , mean(SE) & $1.8(0.2)$ & $2.1(0.2)$ & 0.26 \\
\hline $\begin{array}{l}\text { Number of durable assets owned } \\
\text {,mean(SE) }\end{array}$ & & & \\
\hline Abbreviations: ART: Antretr) & & \\
\hline
\end{tabular}

Abbreviations: ART: Antiretroviral Therapy; WHO: World Health Organization. ${ }^{*} \mathrm{WHO}$ stage $\mathrm{n}=93$ (intervention) and 96 (control). ART days-overall median is 995 days. Durable assets include bicycles, farm implements, mobile phones, household furniture, stove, refrigerator and vehicles

Table 2: Baseline characteristics of study participants. 
Citation: Tirivayi N, Koethe JR, Groot W (2012) Clinic-Based Food Assistance is Associated with Increased Medication Adherence among HIV-Infected Adults on Long-Term Antiretroviral Therapy in Zambia. J AIDS Clinic Res 3:171. doi:10.4172/2155-6113.1000171

\section{Results}

Participants in the intervention $(\mathrm{n}=144)$ and control $(\mathrm{n}=147)$ groups did not differ by age, sex distribution, or mean baseline CD4+ lymphocyte count or BMI ( $\mathrm{p}>0.05$ for all comparisons; Table 2). A significantly higher percentage of the intervention group had a prior clinical diagnosis consistent with WHO disease stage 3 (e.g., pulmonary tuberculosis, pneumonia, chronic diarrhea, among others) compared to the control group ( $37 \%$ versus $17 \%$, respectively; $\mathrm{p}<0.01$ ), which was incorporated into the PSM calculations. The mean duration of ART was not significantly different in the intervention group (777 days) versus the control group (864 days); the median ART duration for the full cohort was 995 days. There were no significant differences in the proportion of married participants, the proportion with no formal education, the mean household size, or the number of durable assets owned by the household.

From the full cohort we estimated propensity scores to generate a sample of matched intervention and control patients. Intervention

\begin{tabular}{|c|c|c|c|c|}
\hline \multirow[t]{2}{*}{ Covariate } & \multicolumn{2}{|l|}{ Mean } & \multirow[t]{2}{*}{ t-statistic } & \multirow[t]{2}{*}{ p-value } \\
\hline & $\begin{array}{l}\text { Intervention } \\
\mathrm{N}=68\end{array}$ & $\begin{array}{l}\text { Control } \\
\mathrm{N}=107\end{array}$ & & \\
\hline Body mass index at baseline, $\mathrm{kg} / \mathrm{m}^{2}$ & 21.0 & 20.6 & 0.65 & 0.52 \\
\hline Age, years & 43 & 41 & 1.26 & 0.21 \\
\hline Female & 0.74 & 0.77 & -0.38 & 0.71 \\
\hline College education & 0.13 & 0.08 & 0.39 & 0.38 \\
\hline Primary education & 0.56 & 0.46 & 0.05 & 0.28 \\
\hline Secondary education & 0.23 & 0.26 & 0.93 & 0.68 \\
\hline Divorced or separated & 0.07 & 0.03 & 0.81 & 0.42 \\
\hline Widowed & 0.20 & 0.14 & 0.77 & 0.44 \\
\hline Never married & 0.07 & 0.09 & -0.53 & 0.60 \\
\hline $\begin{array}{l}\text { Travel from the patient's residence } \\
\text { to the clinic }<1 \text { hour }\end{array}$ & 0.98 & 0.98 & 0.35 & 0.73 \\
\hline $\begin{array}{l}\text { WHO stage III and IV of HIV } \\
\text { disease at baseline }\end{array}$ & 0.51 & 0.55 & -0.49 & 0.62 \\
\hline Participant is unemployed & 0.72 & 0.78 & -0.75 & 0.45 \\
\hline Household does not own a house & 0.71 & 0.69 & 0.19 & 0.85 \\
\hline $\begin{array}{l}\text { Number of HIV-infected household } \\
\text { members }(n)\end{array}$ & 2.89 & 2.93 & -0.16 & 0.87 \\
\hline $\begin{array}{l}\text { Number of disabled household } \\
\text { members }(n)\end{array}$ & 0.10 & 0.17 & -1.11 & 0.27 \\
\hline Household size $(n)$ & 4.80 & 4.36 & 1.44 & 0.15 \\
\hline $\begin{array}{l}\text { Number of durable assets owned } \\
(n)\end{array}$ & 1.89 & 1.95 & -0.21 & 0.84 \\
\hline $\begin{array}{l}\text { Household uses charcoal as fuel } \\
\text { source }\end{array}$ & 0.85 & 0.84 & 0.14 & 0.89 \\
\hline $\begin{array}{l}\text { Total population in locality/area } \\
\text { served by clinic }(n)\end{array}$ & 97,000 & 98,000 & -0.38 & 0.71 \\
\hline
\end{tabular}

'Data expressed as a proportion unless otherwise specified. Total $\mathrm{N}$ for matching is 175 reduced to 168 observations after imposing common support ( 7 treated cases not on support). Overall estimates, $\mathrm{N}=61$ (intervention), 107 (control).

Table 3: Propensity score estimation: mean differences of covariates after matching. patients whose estimated propensity score was above the maximum or below the minimum propensity score for the control group did not have "common support" in the control group and were dropped from the matched sample; we identified 175 cases for matching, which were reduced to 168 observations after imposing common support ( $\mathrm{n}=61$ for intervention arm and $\mathrm{n}=107$ for control arm). After matching, we tested for the equality of means for each covariate included in the probit regression and found that none of the covariates remained significantly different between the intervention and control groups; hence we met the condition for successful matching (Table 3).

Table 4 shows the PSM estimates for adherence to ART (i.e., the MPR). The raw estimates of MPR before matching show an insignificant difference between the intervention and control groups $(0.07 \%$ difference, $95 \%$ CI:-0.002 to $1.4, \mathrm{p}=0.51$ ). The result for the overall matched sample is a significant average treatment effect on the treated (ATT) for medication adherence. The average impact of food assistance on MPR is $9.5 \%$ ( $95 \% \mathrm{CI}: 4.9$ to $14.0, \mathrm{p}<0.01$ ); the intervention group on average has optimal adherence $(98 \%)$ while the control group has suboptimal adherence (89\%). Table 5 shows the proportion of patients with optimal adherence stratified by the clinics. As seen in the table, the matched sample comprises four treated clinics and three intervention clinics. Observations from one clinic (George) did not suit the matching requirements and were thus not included in the analysis. Ultimately, all estimates in the study are based on four control clinics and three intervention clinics. From the intervention clinics, $93 \%$ of Chawama and $90 \%$ Mtendere patients have optimal adherence (MPR $>95 \%$ ). One intervention clinic, Kanyama has too few observations in the matched sample hence its results (25\% of patients adherent) may be an outlier. Among the control clinics, only $59 \%$ of Bauleni, $73 \%$ of Chilenje, $83 \%$ of Matero and $88 \%$ of Chipata patients are optimally adherent. That is an average of around $25 \%$ who are not adherent among all control clinics compared to just $8 \%$ for the intervention clinics (calculation excludes Kanyama, which has too few observations).

We then investigated the conditional estimates of the effect of food assistance on various sub-groups of the sample (Table 6). The majority of patients (95\%) were receiving ART prior to the start of the food assistance program (the remainder started ART and assistance concurrently), and we assess the relationship between duration of ART and the effect size associated with food assistance. Assistance has a larger effect on adherence for patients who had been on ART for less than the median treatment duration (995 days) compared to the overall estimates. For those on ART less than 995 days, food assistance was associated with a $14.5 \%$ higher MPR (95\% CI: 6.3 to 22.7, p<0.01). For patients who had been on ART for duration more than the median of 995 days, food assistance appears to have no significant effect $(p=0.91)$. We also calculated the conditional estimates of the effect of food assistance on various sub-groups of the sample (Table 6). The majority of patients (95\%) were receiving ART prior to the start of the food assistance program (the remainder started ART and assistance concurrently), and we assess the relationship between duration of ART

\begin{tabular}{|c|c|c|c|c|c|c|}
\hline Overall estimates & Intervention group $(n=133)$ & Control group ( $n=147$ ) & Mean difference $(95 \% \mathrm{Cl})$ & Standard error & t-statistic & $p$-value \\
\hline \multirow{2}{*}{$\begin{array}{l}\text { Before Matching } \\
\text { Medication possession ratio }\end{array}$} & $97 \%$ & $96 \%$ & $0.07 \%(-0.002,1.4)$ & 0.01 & 0.66 & 0.51 \\
\hline & Intervention group $(n=61)$ & Control group ( $n=107$ ) & $\begin{array}{l}\text { Mean difference } \\
(95 \% \mathrm{Cl})\end{array}$ & Standard error & t-statistic & p-value \\
\hline $\begin{array}{l}\text { After matching } \\
\text { Medication possession ratio }\end{array}$ & $98 \%$ & $89 \%$ & $\begin{array}{l}9.5 \% \\
(4.9,14.0)\end{array}$ & 0.02 & 4.06 & $<0.01$ \\
\hline
\end{tabular}

Total $\mathrm{N}$ for unmatched sample for the medication possession ratio is 280 (11 missing observations). Total $\mathrm{N}$ for matched sample is 175 reduced to 168 observations after imposing common support ( 7 treated cases not on support). Overall estimates, $\mathrm{N}=61$ (intervention), 107 (control).

Table 4: Propensity score matching estimates of the impact of food assistance on adherence after six months. 
Citation: Tirivayi N, Koethe JR, Groot W (2012) Clinic-Based Food Assistance is Associated with Increased Medication Adherence among HIV-Infected Adults on Long-Term Antiretroviral Therapy in Zambia. J AIDS Clinic Res 3:171. doi:10.4172/2155-6113.1000171

and the effect size associated with food assistance. Assistance has a larger effect on adherence for patients who had been on ART for less than the median treatment duration (995 days) compared to the overall estimates. For those on ART less than 995 days, food assistance was associated with a $14.5 \%$ higher MPR (95\% CI: 6.3 to 22.7, p<0.01). For patients who had been on ART for duration more than the median of 995 days, food assistance appears to have no significant effect ( $\mathrm{p}=0.91$ ). We next performed a series of sub-analyses to determine how long the effect of food assistance on medication adherence persists after ART initiation. We started with an analysis of the minimum ART duration recorded in the sample which is 154 days and added a progressively

\begin{tabular}{|l|l|l|l|}
\hline By Clinic & Intervention group $\mathbf{( n = 6 1 )}$ & Control group $\mathbf{( n = 1 0 7 )}$ & $\mathbf{n}$ \\
\hline Clinic $\%$ & & & \\
\hline Chawama & $93 \%$ & & 27 \\
\hline *Kanyama & $25 \%$ & & 4 \\
\hline Mtendere & $90 \%$ & & 30 \\
\hline George & n/a & & $n / a$ \\
\hline Bauleni & & $59 \%$ & 36 \\
\hline Chilenje & & $73 \%$ & 28 \\
\hline Chipata & & $88 \%$ & 25 \\
\hline Matero & & $83 \%$ & 17 \\
\hline
\end{tabular}

Total $\mathrm{N}$ for matched sample is 175 reduced to 168 observations after imposing common support ( 7 treated cases not on support). Overall estimates, $N=61$ (intervention), 107 (control). Observations from George clinic not included by the matching model. *Only 4 Observations for Kanyama.

Table 5. Proportion of patients who are adherent by clinic (MPR $>95 \%$ ). greater number days for each sub-analysis. For patients ART duration of 154 days or greater, food assistance has a significant effect of about 9.5\% (95\% CI: 4.9 to $14, \mathrm{p}<0.01)$. However, the significant effect appears to end at around 230 days ( $10.5 \%$ difference, $95 \%$ CI: 6,3 to $15, \mathrm{p}<0.01$ ). For patients with ART duration equal to or greater than 231 days food assistance does not appear to have a significant effect (95 CI: -2.1 to 3, $\mathrm{p}=0.67$ ). Hence, from the analysis, it would seem that food assistance is associated with a beneficial effect for the first 230 days after ART initiation (approximately 7.5 months).

We also assess the effect of food assistance on MPR after stratifying by disease stage, BMI and CD4+ lymphocyte count. When we compare patients with a BMI below $18.5 \mathrm{~kg} / \mathrm{m}^{2}$ (i.e., the WHO threshold for malnutrition) to those above this value, we find that food assistance significantly improved MPR for malnourished patients by 33.3\% (95\% CI: 10.8 to $55.9, \mathrm{p}<0.01$ ), compared to $0.03 \%$ (95\% CI: -0.019 to 0.02 , $\mathrm{p}=0.98$ ) for normal-weight patients. Food assistance also improved the MPR for patients with HIV disease stage 3 or 4 by $20.9 \%$, which approached statistical significance (95\% CI: -2.8 to $44.6, \mathrm{p}=0.09$ ), but not for patients with disease stages 1 or 2 ( $0.8 \%$ increase in MPR, $95 \%$ CI: -2.6 to $4.1 ; \mathrm{p}=0.65)$. Finally, food assistance significantly improved MPR for patients whose CD4+ lymphocyte count was $\leq 350$ cells/ $\mu$ l by $18.9 \%$ (95\% CI: 10.8 to $27.0, \mathrm{p}<0.01$ ) while for patients with $>350$ cells/ $\mu \mathrm{l}$, MPR significantly improved by $4.8 \%$ ( $95 \%$ CI: 1.8 to $7.7, \mathrm{p}<0.01$ ).

The PSM estimates evaluating the impact of food assistance on BMI and CD4+ lymphocyte count outcomes found no significant differences between study arms. The 6 month change (January to July 2009) in BMI

\begin{tabular}{|c|c|c|c|c|c|c|c|}
\hline & $\begin{array}{l}\text { Intervention } \\
(n=61)\end{array}$ & group & Control group $(n=107)$ & $\begin{array}{l}\text { Mean Difference } \\
(95 \% \mathrm{Cl})\end{array}$ & Standard Error & t-statistic & $P$ value \\
\hline \multicolumn{8}{|l|}{ Conditional Estimates } \\
\hline \multicolumn{8}{|l|}{ Duration of $A R T$} \\
\hline MPR if ART $\geq 995$ days $(n)$ & $\begin{array}{l}97 \% \\
(31)\end{array}$ & & $\begin{array}{l}98 \% \\
(53)\end{array}$ & $\begin{array}{l}-1.1 \% \\
(-2.5,2.3)\end{array}$ & 0.01 & -0.11 & 0.91 \\
\hline MPR if ART <995 days (n) & $\begin{array}{l}98 \% \\
(37)\end{array}$ & & $\begin{array}{l}84 \% \\
(53)\end{array}$ & $\begin{array}{l}14.5 \% \\
(6.3,22.7)\end{array}$ & 0.04 & 3.46 & $<0.01$ \\
\hline MPR if ART $\geq 154$ days (n) & $\begin{array}{l}98 \% \\
(61)\end{array}$ & & $\begin{array}{l}89 \% \\
(107)\end{array}$ & $\begin{array}{l}9.5 \% \\
(4.9,14)\end{array}$ & 0.02 & 4.06 & $<0.01$ \\
\hline MPR if ART $\geq 230$ days (n) & $\begin{array}{l}99 \% \\
(60)\end{array}$ & & $\begin{array}{l}88 \% \\
(103)\end{array}$ & $\begin{array}{l}10.7 \% \\
(6.3,15)\end{array}$ & 0.02 & 4.71 & $<0.01$ \\
\hline MPR if ART $\geq 231$ days $(n)^{*}$ & $\begin{array}{l}99 \% \\
(60)\end{array}$ & & $\begin{array}{l}98 \% \\
(101)\end{array}$ & $\begin{array}{l}0.6 \% \\
(-2.1,3)\end{array}$ & 0.01 & 0.42 & 0.67 \\
\hline MPR if $A R T \geq 250$ days (n) & $\begin{array}{l}99 \% \\
(59)\end{array}$ & & $\begin{array}{l}98 \% \\
(98)\end{array}$ & $\begin{array}{l}0.05 \% \\
(-1.2,2)\end{array}$ & 0.009 & 0.06 & 0.95 \\
\hline \multicolumn{8}{|l|}{ Baseline BMI, kg/m² } \\
\hline MPR if $\mathrm{BMI}$ is $<18.5(\mathrm{n})$ & $\begin{array}{l}99 \% \\
(12)\end{array}$ & & $\begin{array}{l}66 \% \\
(15)\end{array}$ & $\begin{array}{l}33.3 \% \\
(10.8,55.9)\end{array}$ & 0.12 & 2.9 & $<0.01$ \\
\hline MPR if $B M I$ is $\geq 18.5(n)$ & $\begin{array}{l}98.35 \% \\
(45)\end{array}$ & & $\begin{array}{l}98.32 \% \\
(92)\end{array}$ & $\begin{array}{l}0.03 \% \\
(-0.019,0.02)\end{array}$ & 0.01 & 0.03 & 0.98 \\
\hline \multicolumn{8}{|l|}{ Baseline Stage of Disease } \\
\hline MPR if HIV disease stage I or II (n) & $\begin{array}{l}99 \% \\
(31)\end{array}$ & & $\begin{array}{l}98 \% \\
(68)\end{array}$ & $\begin{array}{l}0.8 \% \\
(-2.6,4.1)\end{array}$ & 0.02 & 0.45 & 0.65 \\
\hline MPR if HIV disease stage III or IV (n) & $\begin{array}{l}99 \% \\
(15)\end{array}$ & & $\begin{array}{l}78 \% \\
(19)\end{array}$ & $\begin{array}{l}20.9 \% \\
(-2.8,44.6)\end{array}$ & 0.12 & 1.73 & 0.09 \\
\hline \multicolumn{8}{|l|}{ Baseline CD4 count, , mean cells/ $\mu$ l } \\
\hline MPR if CD4+lymphocyte count $\leq 350(n)$ & $\begin{array}{l}99 \% \\
(24)\end{array}$ & & $\begin{array}{l}80 \% \\
(44)\end{array}$ & $\begin{array}{l}18.9 \% \\
(10.8,27.0)\end{array}$ & 0.04 & 4.57 & $<0.01$ \\
\hline MPR if CD4+ lymphocyte count >350 (n) & $\begin{array}{l}98 \% \\
(44)\end{array}$ & & $\begin{array}{l}94 \% \\
(63)\end{array}$ & $\begin{array}{l}4.8 \% \\
(1.8,7.7)\end{array}$ & 0.02 & 3.19 & $<0.01$ \\
\hline
\end{tabular}

Abbreviations: ART, antiretroviral therapy; BMI, body mass index; MPR, medication possession ratio. Total $\mathrm{N}$ for matching is 175 reduced to 168 observations after imposing common support (7 treated cases not on support). Overall estimates, $\mathrm{N}=61$ (intervention), 107 (control).

*Difference in MPR between arms was no longer significant when participants with 231 days of ART or greater were included in the analysis

Table 6: Conditional estimates of the impact of food assistance on adherence after six months. 
was $0.18 \mathrm{~kg} / \mathrm{m}^{2}$ in the intervention group and $0.25 \mathrm{~kg} / \mathrm{m}^{2}$ in the control group ( $\mathrm{p}=0.84$ ), while the change in $\mathrm{CD} 4+$ lymphocyte count was 3 cells $/ \mu \mathrm{l}$ versus -28 cells $/ \mu \mathrm{l}$, respectively $(\mathrm{p}=0.47)$. Conditional estimates of BMI and CD4+ count stratified by duration of ART, baseline BMI, baseline disease stage and baseline CD4+ lymphocyte count were also non-significant.

\section{Discussion}

This analysis of a clinic-level food-assistance program providing household rations to food insecure, HIV-infected adults on long-term ART in Lusaka, Zambia found a positive effect on patient compliance with pharmacy medication refill visits, a validated surrogate measure for ART adherence, but found no observable effect on weight gain or CD4+ lymphocyte count. The effect of food rations on MPR are similar to the analysis by Cantrell et al. conducted among patients starting ART in the initial years of the rapid scale up of HIV treatment in Zambia, and suggests that assistance may still have an important role in promoting continuity of treatment among long-term ART recipients during periods of food insecurity [17]. However, the absence of an effect on weight and immune recovery in our analysis may indicate that these common study endpoints are less relevant for assessing the effect of short term interventions (6 months of food assistance in our study) among patients who have clinically 'stabilized' after being on ART for months to years.

Our results found a greater impact of food assistance on adherence among patients in the first 3 years of treatment, and particularly in the first 230 days (7.5 months) after ART initiation. Additionally, the effect was greater among those with several indicators of more advanced illness, including lower BMI, higher HIV disease stage, and greater CD4+ lymphocyte depletion. This may indicate that patients with inadequate nutrition and/or more advanced disease have greater barriers to care and are more likely to be incentivized by food assistance to attend scheduled clinic visits $[9,27]$. Further studies to understand the determinants of food insecurity and interventions to target these particular groups could have an important impact on second-line ART usage, cost-effectiveness of treatment, and overall program health outcomes. However, we also acknowledge that measuring actual patient adherence to ART is difficult in resource constrained settings where HIV1-RNA tests are not regularly available and drug delivery problems delay the administration of ART drugs to patients. Additionally, the use of the MPR, while validated against virologic suppression data in prior analyses, does not measure all elements of adherence, especially ART self-administration patterns. Further studies are needed to explore the linkages between food assistance, actual patient behavior, and the maintenance of HIV-1 virologic suppression. However, a plausible explanation for our findings is that food assistance does incentivize food insecure patients on stable ART to attend clinic visits, likely by influencing decisions regarding the time and expense of travelling to the clinic versus the need to work and generate income.

Our analysis of clinical data found no significant effect of food assistance on weight change or CD4+ lymphocyte recovery, which is similar to the results of prior studies $[13,17]$. The lack of a significant effect on weight gain could be explained by several factors. First, the food assistance program targeting criteria were based on household food insecurity and vulnerability rather than poor nutritional status of the HIV-infected individual. Second, most assistance recipients were not severely malnourished, had been established on ART for several years, and had demonstrated substantial immune reconstitution as evidenced by a baseline mean CD4+ lymphocyte count above 300 cells/ $\mu$ l. Third, the food commodities provided were mainly maize flour, lentils and oil augmented with fortified blended corn and soya flour, rather than the energy-dense, ready-to-use therapeutic feeding products provided in some prior randomized supplementation trials $[14,16]$. Lastly, sharing of food rations within the family was likely high, and the actual intake by the HIV-infected individual may have been variable. The lack of a positive effect on weight gain or immune recovery does not imply that food assistance to ART patients cannot improve these outcomes, but it does suggest that improvement in these clinical markers should not be assumed as a collateral benefit of household-level assistance programs.

Our study has several limitations. We used an observational, nonrandomized methodology, and the sample size may have been too small to detect differences in some endpoints. Since we utilized a retrospective cohort design, patients lost to follow up were most likely excluded from our sample, which could have affected our study outcome. However, we utilized interviewer blinding, and the analysis outcomes were not mentioned at recruitment in an attempt to minimize selection bias. Another limitation of the study is that we did not have baseline (preintervention) adherence measurements, but to reduce confounding we matched intervention and control study clinics on several factors related to facility type and patient outcomes, and we incorporated multiple conditioning variables in the model for predicting the propensity score, including demographics, disease stage, education, marriage, distance to health facility, several surrogate markers of economic status, and household characteristics. Despite these clinic-level and participantlevel techniques, some residual confounding may have remained.

However, despite our study facing challenges of missing data and the limitations in our design, we believe our study data allow for reasonable analysis and findings that can help explain the role of food assistance in HIV treatment programs. Our findings are also generalizable to other settings, especially since our study derives its data from a common and frequently used program design where patients cannot be easily randomized due to ethical issues but receive the usual routine clinical care provided to ART patients in low income settings [13]. Our findings also concur with results from other studies carried out in similar program settings with the same data challenges $[13,17]$.

In conclusion, we found that clinic-based household food assistance for 6 months increased medication adherence in a cohort of food insecure, HIV-infected Zambian adults on long-term ART, but had no effect on weight or CD4+ lymphocyte count. Our results suggest that the provision of household rations may have an incentivizing effect with direct clinical relevance. Given the high prevalence of both food insecurity and HIV infection in many areas of sub-Saharan Africa, the provision of clinic-based food assistance to improve household welfare and food security may be an important adjunct to ART treatment efforts, though further studies are needed to define the target population and the optimal intervention.

\section{Acknowledgements}

The authors would like to acknowledge the valuable comments received from the anonymous reviewers. The authors would also like to acknowledge Mark Giganti Carolyn Bolton at the Centre for Infectious Diseases Research in Zambia, Saskia De Pee and Martin Bloem of the World Food Program-Rome, and Calum McGregor at the World Food Program-Zambia for their assistance in conducting this study. The authors are grateful for the efforts of the Enumerators, Community Liaison Officers, Food Committee Members, Adherence Support Workers, Support Group Leaders and Home Based Caregivers who implemented the food assistance program and facilitated the study data collection. Finally, the authors acknowledge the Zambian Ministry of Health for their consistent support of operational HIV research, and the World Food Program Regional and Zambia offices, the Central Statistical Office of the Republic of Zambia, and the Programme for Urban Self Help.

Investigator support was provided by the NIH Fogarty International Center 
Citation: Tirivayi N, Koethe JR, Groot W (2012) Clinic-Based Food Assistance is Associated with Increased Medication Adherence among HIV-Infected Adults on Long-Term Antiretroviral Therapy in Zambia. J AIDS Clinic Res 3:171. doi:10.4172/2155-6113.1000171

(R24-TW007988), UNAIDS, the World Health Organization, the Ford Foundation and the Poverty, Equity and Growth Network. The funding bodies were not involved in the study design, data collection, analysis, interpretation, or manuscript preparation.

\section{Conflict of Interest Statement}

The authors declare that they have no conflicts of interest.

\section{Authors' contributions}

NT was the principal investigator of the study. All authors (NT, JK, WG) participated in the planning and conceptualization of the research. NT was responsible for the study design and primary data collection activities while JK assisted in obtaining clinical data. NT was responsible for data analysis with input from WG. NT and JK drafted the article, and all authors participated critically revising the manuscript and approved the revised manuscript.

\section{References}

1. Weiser SD, Tsai AC, Gupta R, Frongillo EA, Kawuma A, et al. (2012) Food insecurity is associated with morbidity and patterns of healthcare utilization among HIV-infected individuals in a resource-poor setting. AIDS 26: 67-75.

2. Weiser SD, Tuller DM, Frongillo EA, Senkungu J, Mukiibi N, et al. (2010) Food Insecurity as a Barrier to Sustained Antiretroviral Therapy Adherence in Uganda. PLoS One 5: e10340.

3. Schaible UE, Kaufmann SH (2007) Malnutrition and infection: complex mechanisms and global impacts. PLoS Med 4: e115.

4. World Health Organisation (2003) Scaling up antiretroviral therapy in resourcelimited settings: Treatment guidelines for a public health approach. WHO: Geneva.

5. de Pee S, Semba RD (2010) Role of nutrition in HIV infection: review of evidence for more effective programming in resource-limited settings. Food Nutr Bull 31: S313-344.

6. Gupta A, Nadkarni G, Yang WT, Chandrasekhar A, Gupte N, et al. (2011) Early Mortality in Adults Initiating Antiretroviral Therapy (ART) in Low- and MiddleIncome Countries (LMIC): A Systematic Review and Meta-Analysis. PLoS One 6: e28691.

7. Stringer JS, Zulu I, Levy J, Stringer EM, Mwango A, et al. (2006) Rapid scaleup of antiretroviral therapy at primary care sites in Zambia: feasibility and early outcomes. JAMA 296: 782-793.

8. Johannessen A, Naman E, Ngowi BJ, Sandvik L, Matee MI, et al. (2008) Predictors of mortality in HIV-infected patients starting antiretroviral therapy in a rural hospital in Tanzania. BMC Infect Dis 8: 52.

9. Bukusuba J, Kikafunda JK, Whitehead RG (2007) Food security status in households of people living with HIVIAIDS (PLWHA) in a Ugandan urban setting. Br J Nutr 98: 211-217.

10. Koethe JR, Lukusa A, Giganti MJ, Chi BH, Nyirenda CK, et al. (2010) Association between weight gain and clinical outcomes among malnourished adults initiating antiretroviral therapy in Lusaka, Zambia. J Acquir Immune Defic Syndr 53: 507-513.

11. Willig JH, Echevarria J, Westfall AO, Iglesias D, Henostroza G, et al. (2010) Durability of initial antiretroviral therapy in a resource-constrained setting and the potential need for zidovudine weight-based dosing. J Acquir Immune Defic Syndr 53: 215-221.

12. Ivers LC, Chang Y, Gregory Jerome J, Freedberg KA (2010) Food assistance is associated with improved body mass index, food security and attendance at clinic in an HIV program in central Haiti: a prospective observational cohort study. AIDS Res Ther 7: 33

13. Rawat R, Kadiyala S, McNamara PE (2010) The impact of food assistance on weight gain and disease progression among HIV-infected individuals accessing AIDS care and treatment services in Uganda. BMC Public Health 10: 316.

14. Ndekha MJ, van Oosterhout JJ, Zijlstra EE, Manary M, Saloojee H, et al. (2009) Supplementary feeding with either ready-to-use fortified spread or corn-soy blend in wasted adults starting antiretroviral therapy in Malawi: randomised, investigator blinded, controlled trial. BMJ 338: b1867.

15. Koethe JR, Chi BH, Megazzini KM, Heimburger DC, Stringer JS (2009) Macronutrient supplementation for malnourished HIV-infected adults: a review of the evidence in resource-adequate and resource-constrained settings. Clin Infect Dis 49: 787-798.
16. Ndekha M, van Oosterhout JJ, Saloojee H, Pettifor J, Manary M (2009) Nutritional status of Malawian adults on antiretroviral therapy 1 year after supplementary feeding in the first 3 months of therapy. Trop Med Int Health 14: 1059-1063.

17. Cantrell RA, Sinkala M, Megazinni K, Lawson-Marriott S, Washington S, et al. (2008) A pilot study of food supplementation to improve adherence to antiretroviral therapy among food-insecure adults in Lusaka, Zambia. J Acquir Immune Defic Syndr 49: 190-195.

18. Thirumurthy H, Zivin JG, Goldstein M (2008) The Economic Impact of AIDS Treatment: Labor Supply in Western Kenya. J Hum Resour 43: 511-552.

19. Wools-Kaloustian K, Kimaiyo S, Diero L, Siika A, Sidle J, et al. (2006) Viability and effectiveness of large-scale HIV treatment initiatives in sub-Saharan Africa: experience from western Kenya. AIDS 20: 41-48.

20. Goldman JD, Cantrell RA, Mulenga LB, Tambatamba BC, Reid SE, et al. (2008) Simple adherence assessments to predict virologic failure among HIV-infected adults with discordant immunologic and clinical responses to antiretroviral therapy. AIDS Res Hum Retroviruses 24: 1031-1035.

21. Messou E, Chaix ML, Gabillard D, Minga A, Losina E, et al. (2011) Association between medication possession ratio, virologic failure and drug resistance in HIV-1-infected adults on antiretroviral therapy in Cote d'Ivoire. J Acquir Immune Defic Syndr 56: 356-364.

22. Chi BH, Cantrell RA, Zulu I, Mulenga LB, Levy JW, et al. (2009) Adherence to first-line antiretroviral therapy affects non-virologic outcomes among patients on treatment for more than 12 months in Lusaka, Zambia. Int J Epidemiol 38 746-756.

23. Maggiolo F, Airoldi M, Kleinloog HD, Callegaro A, Ravasio V, et al. (2007) Effect of adherence to HAART on virologic outcome and on the selection of resistance-conferring mutations in NNRTI- or PI-treated patients. HIV Clin Trials 8: 282-292.

24. Leuven E, Sianesi B, PSMATCH2: Stata module to perform full Mahalanobis and propensity score matching, common support graphing, and covariate imbalance testing. Version 3.1.5.

25. Smith JA, Todd PE (2001) Reconciling Conflicting Evidence on the Performance of Propensity-Score Matching Methods. American Economic Review 91: 112118.

26. Heckman JJ, Ichimura H, Todd P (1998) Matching as an Econometric Evaluation Estimator. The Review of Economic Studies Limited 65: 261-294.

27. Hardon AP, Akurut D, Comoro C, Ekezie C, Irunde HF, et al. (2007) Hunger waiting time and transport costs: time to confront challenges to ART adherence in Africa. AIDS Care 19: 658-665. 